\title{
Psicologia e Educação no Brasil: Uma Visão da História e Possibilidades nessa Relação
}

\author{
Raquel S. L. Guzzo ${ }^{1}$ \\ Adinete S. C. Mezzalira \\ Ana Paula Gomes Moreira \\ Raquel Pondian Tizzei \\ Walter Mariano de Faria Silva Neto \\ Pontifícia Universidade Católica (Campinas)
}

\begin{abstract}
RESUMO - O presente artigo discute alguns elementos históricos da relação entre Psicologia e Educação no Brasil, enfatizando sua dimensão prática e teórica. Ou seja, apresenta a Psicologia Escolar e os fundamentos que subsidiam essa prática, assim como a produção intelectual decorrente. Ao mesmo tempo, discute os limites e dificuldades presentes nesse processo durante os últimos 20 anos, indicando a importância da área no cenário político social brasileiro e suas direções futuras.
\end{abstract}

Palavras-chave: Psicologia Escolar; Psicologia Crítica; História da Psicologia.

\section{Psychology and Education in Brazil: A Historical Point of View and Possibilities in that Relation}

\begin{abstract}
The present article discusses some historical elements of the relation between Psychology and Education in Brazil, emphasizing its practical and theoretical dimension. That is, it presents School Psychology and the foundations that support this practice as well as the resulting intellectual production. At the same time, it discusses the limits and difficulties present in this process over the past 20 years, indicating the importance of the area in the Brazilian social-political conjuncture and its future directions.
\end{abstract}

Keywords: School Psychology; Critical Psychology; History of Psychology.

O amadurecimento de uma profissão está relacionado ao quanto uma determinada área de conhecimento se consolida e à perspectiva da relação que o conhecimento teórico estabelece com a prática e com as demandas da realidade. A relação da Psicologia com a Educação não é diferente. Apesar de estreita e antiga, é no bojo das circunstâncias concretas que ela se consolida em teoria e prática. Discutir alguns elementos presentes na história da Psicologia Escolar no Brasil, como parte do objetivo deste trabalho, significa dizer sobre essa relação e, ao mesmo tempo, deixar clara a perspectiva que fundamenta nossa análise, para que seja possível debater o futuro e as possibilidades de avanços na consolidação dessa área, justificados pela posição que assumimos da realidade brasileira.

O presente artigo está estruturado em três partes: a primeira resume alguns elementos importantes da realidade brasileira para a compreensão da história da área e de seu momento atual no Brasil, especialmente no que se refere à atuação e formação profissional; a segunda destaca as bases teóricas e metodológicas que sustentaram as práticas e produções científicas da área nos últimos 20 anos, com ênfase na produção nacional; a terceira discute o impacto dessa trajetória no desenvolvimento da área, tanto no cenário nacional quanto internacional, e apresenta uma discussão sobre o futuro, focalizando a formação básica, assim como sua produção científica e prática profissional.

1 Endereço para correspondência: Rua Santa Monica, 136, casa 1. Campinas, SP. CEP 13.100-101. E-mail: rguzzo@mpc.com.br.

\section{Uma Visão Histórica da Área}

A leitura histórica da produção e consolidação de uma área do conhecimento pode trazer diferentes elementos e análises, conforme posições políticas e visões de mundo que tenham seus interlocutores. Validar a história é uma tarefa difícil. Para Prilleltenski (2003), o conceito de validade psicopolítica ajuda a dar sentido às análises da história por suas consequências no cotidiano da vida e põe em curso uma leitura das possibilidades presentes na construção de próximos passos e produções necessárias para dar consistência à área. $\mathrm{O}$ conceito de história de que nos utilizamos neste trabalho parte dos fundamentos materialistas da história que, em Benjamim (1987), distingue-se de uma mera descrição da passagem do tempo ou um nexo causal entre vários momentos do passado. A historiografia marxista tem, em sua base, um princípio construtivo, que reconhece a imobilização dos acontecimentos e busca uma oportunidade de extrair da época passada uma determinada condição de vida, que preservada e transcendida, fornece semente para a superação das condições do presente - do "agora", no qual se infiltraram estilhaços do passado. Essa é a tentativa que fazemos ao apresentarmos aqui alguns elementos da história da Psicologia Escolar no Brasil.

Por essa razão, a compreensão da trajetória histórica da Psicologia Escolar somente se torna possível pelo estudo 
acerca do papel da Psicologia como ciência e profissão, que surge e se aprimora em um momento histórico e social de criação e consolidação do capitalismo. Embora não sendo esse o principal objetivo deste artigo, é importante destacar que o desenvolvimento do capitalismo instaurou uma nova forma de relação social, marcada pelas relações de produção no século XIX, que impactaram as relações no âmbito da família, especialmente em relação ao papel da mulher nos espaços sociais (Parker, 2007). Essas novas relações de poder foram sustentadas por diferentes produções de conhecimento, das quais a Psicologia fez parte. Assim, a Psicologia, como uma disciplina, desempenhou um importante papel e uma precisa função sob o capitalismo - a de contribuir para que essa nova forma de sociabilidade pudesse manter o desenvolvimento econômico.

Antes de iniciar com os apontamentos históricos que caracterizam os passos da Psicologia Escolar no Brasil, é preciso entender que a Psicologia, desenvolvida e aplicada em outros países, em outras épocas históricas, serviu de inspiração às nossas práticas e conhecimento, mas pouco respondeu às demandas sociais presentes no cotidiano das escolas brasileiras. Por isso, é preciso um movimento crítico e atualizador dessa prática, com as necessárias e consequentes revisões teóricas que a sustentem e forneçam diretrizes para seu desenvolvimento.

\section{O cenário brasileiro}

O Brasil é um país com dimensões continentais e, portanto, bastante diverso em suas características, o que torna ainda mais difícil uma tentativa de universalizar algumas de suas principais condições. Apesar da publicação de indicadores que representam grandes transformações sociais, políticas e econômicas nos últimos anos, (tais como, escolaridade de crianças e jovens, renda familiar, postos de emprego, para citar apenas alguns), as transformações vividas nas últimas décadas, no entanto, nem sempre apontam para o que tem sido denominado "progresso" (Albuquerque, 1995; Januzzi, 2005). De acordo com os autores, o país acumula evidências das consequências da industrialização ocorridas nas últimas décadas do século passado - crescimento econômico com desigualdade social. E essa receita de desenvolvimento, continua presente, talvez até mais acentuada nos dias de hoje, sem que seja possível visualizar a realidade concreta, cada vez mais desigual e violenta, sobretudo, no sistema de ensino cindido em público e privado.

Apenas para evidenciar essa desigualdade, dados publicados pelo Instituto de Pesquisa Econômica Aplicada (IPEA), por Santos e Rosas (2010), apontam que, de 2008 para 2009, a Pesquisa Nacional por Amostra de Domicílios (Pnad), que divide os grupos sociais com base na renda familiar em estratos percentuais de $10 \%$ em 10\%, mostrou que o índice de Gini passou de 0,521 para 0,518. Embora os dados apontem para uma pequena queda nesse índice, o que poderia significar uma queda nos níveis de desigualdade no Brasil, eles não beneficiaram os $10 \%$ mais pobres da população, que não tiveram aumento na renda mensal como consequência do trabalho. No estrato seguinte, de $10 \%$ a $20 \%$ mais pobres, a renda subiu apenas $0,65 \%$. Já para os $10 \%$ mais ricos, o aumento da renda foi de $1,75 \%$. Os autores defendem que, o que sustentou a queda do índice Gini e, portanto, a referência à desigualdade social, foram camadas sociais que recebem valores intermediários de renda, ou seja, que recebem entre $\mathrm{R} \$ 459,00$ e $\mathrm{R} \$ 710,00$ de receita média mensal proveniente do trabalho. ${ }^{2}$

Dados do Instituto Brasileiro de Geografia e Estatística (IBGE), discutidos por Melo, Setti, Lins e Weber (2010), expressam que o analfabetismo atingiu 9,7\% da população brasileira, em 2009, o que corresponde a 14,1 milhões de pessoas, mas nesses índices não estão incluídos os analfabetos funcionais, de modo que o analfabetismo efetivamente pode ser bem maior. Já a taxa de escolarização de crianças de 6 a 14 anos atingiu 97,6\% dessa população. Esses dados mostram que, mesmo com a quase totalidade de crianças ingressando na escola com 6 anos, isto não assegura sua permanência ou que se alfabetizem na qualidade esperada para a continuidade de seus estudos. Os relatórios oficiais não revelam, com a devida clareza, a evasão da escola ou as dificuldades que estão subentendidas nos indicadores de analfabetismo do país.

Esse quadro torna-se um importante cenário para a análise da inserção profissional da Psicologia brasileira, considerando que o campo de atuação - as escolas e outros espaços educativos não formais - revela e mantém a desigualdade em sua essência por sua própria estrutura e dinâmica. A realidade da escola pública brasileira é muito diferente da realidade da escola privada e, é na escola pública que estudam a quase totalidade das crianças brasileiras. Com isso, reproduz-se, em todos os níveis de escolarização, o despreparo e as dificuldades para que a Psicologia possa ser ferramenta de promoção do desenvolvimento de crianças e adolescentes sem políticas públicas para o ingresso dos profissionais de Psicologia na rede pública de ensino, cada vez mais, esse cenário se distancia da formação profissional e de seu campo de produção intelectual.

Com relação à atuação do profissional de Psicologia no campo educativo, é preciso levar em conta uma multiplicidade de aspectos que passam por uma análise da realidade de maneira ampla e crítica, envolvendo um corpo de conhecimento não apenas da Psicologia, mas de outras áreas de saberes e práticas, como a Filosofia, a História, a Pedagogia etc. (Maluf, 1994; Maluf \& Cruces, 2008; Meira, 2000).

A história da Psicologia no Brasil, de acordo com Patto (1984), divide-se em três grandes períodos: o primeiro, de 1906 a 1930, na $1^{a}$ República, marcado por estudos de laboratório num modelo europeu e sem a preocupação de intervir na realidade; o segundo, de 1930 a 1960, marcado pelo tecnicismo de origem norte-americana; e o terceiro, a partir de 1960, quando o trabalho do psicólogo passa a ter uma forma mais adaptacionista - a figura do psicólogo escolar era tida como a de solucionador de problemas, especialmente os de comportamento e aprendizagem. Outros autores também analisaram essa área e sua relação com a realidade política, econômica e social.

Almeida (2002), por exemplo, descreve, primeiramente, que a Psicologia associada aos experimentos laboratoriais marcou o surgimento da área, no início do século, sem que,

2 Mais dados sobre esses indicadores podem ser acessados no artigo dos autores pela página do IPEA (www.ipea.gov.br). 
contudo, tenha tido impacto de mudança na realidade. Posteriormente, na segunda metade do século passado, o modelo que vigorou foi o das tendências psicométricas, em especial a aplicação de testes psicológicos, os quais se fundamentavam na proposta clínica voltada para o diagnóstico ou para a mensuração característica da ciência positivista, com vistas à predição e controle. Esse modelo de atuação e o corpo de conhecimento de então contribuíram para a segregação de crianças em salas especiais e classificação de aptos e não aptos para o desenvolvimento nos espaços educativos. Estava aí a raiz da política de exclusão da escola, sobretudo da que se destinava à população mais pobre e oriunda da classe trabalhadora.

Yazlle (1990) aponta que, antes de 1964, mesmo com propostas aparentemente avançadas, a Psicologia exercida no Brasil era comprometida, predominantemente, com o conservadorismo e o reprodutivismo social. Já para Tanamachi (2000), somente a partir de 1980, com a retomada democrática no país, é que passou a ser presente em alguns municípios o trabalho dos psicólogos escolares e, com isso, a construção de um movimento político na área para se repensar a prática profissional nesse campo de atuação.

Não podemos deixar de ressaltar que as desigualdades sociais são mantidas pelas discrepâncias que se concretizam em relação ao nível de escolaridade de crianças e adolescentes que frequentam o ensino público. De acordo com Guzzo, Martinez e Campos (2007), apesar de dados oficiais registrarem uma quase universalidade na matrícula de crianças em idade escolar no Ensino Fundamental, a escalada de abandono e evasão da escola continuava consolidada no país: apenas $36 \%$ se formaram no Ensino Médio e apenas $11 \%$ dos jovens entraram para o Ensino Superior. Um "apartheid educacional" sem precedentes, que exclui cerca de $80 \%$ das crianças, adolescentes e jovens do direito ao estudo completo até o nível superior.

É preciso destacar, também, que somente após 1995 é que o Brasil começou a sistematizar uma forma mais efetiva de publicação de indicadores educacionais que permitissem pensar mais criticamente a realidade educacional. Os Parâmetros Curriculares Nacionais (PCNs) (Ministério da Educação, 1997) é que constituem, de certa forma, um referencial oficial acerca desses indicadores, bem como dos investimentos na área. Por meio dele, tem-se acesso às propostas dos planos educacionais nacionais e internacionais sobre educação (Ministério da Educação, 1993, 1996). Essa medida é implantada em um período posterior à ditadura militar vivida por 25 anos no país.

De acordo com os PCNs, durante as décadas da ditadura militar, a política educacional brasileira recaiu sobre a expansão das oportunidades de escolarização, havendo um aumento expressivo no acesso à escola básica. No entanto, essa determinação não foi acompanhada pela qualificação das condições de trabalho dos docentes e infraestrutura das instituições educativas. Como consequência, inicia-se o desmantelamento do sistema público de ensino e a obediência à agenda neoliberal circunscrita aos empréstimos e ditames do Fundo Monetário Internacional (FMI). Altos índices de repetência e evasão apontavam grande insatisfação de educadores e comunidades com o trabalho realizado nas e pelas escolas. Mesmo com uma determinação de universalização do Ensino Fundamental, decorrente de processos consti- tuintes posteriores à ditadura e no bojo do neoliberalismo implementado no país, a escolaridade das crianças não se mantinha como prioridade política e os desafios tornavam a realidade um quadro desalentador de violação dos direitos fundamentais ao desenvolvimento e aprendizagem de todas as crianças brasileiras. Em 1990, apenas 19\% da população tinham primeiro grau completo, $13 \%$, o nível médio e $8 \%$ possuíam o nível superior. Hoje a realidade mudou em índices, mas substancialmente a exclusão permanece.

Mesmo tendo apresentado significativas mudanças nos indicadores quantitativos, o perfil da educação brasileira durante as duas últimas décadas mantém-se distante dos patamares de uma sociedade que se pretenda justa e igualitária. Ainda vivemos com alta taxa de analfabetismo e com crianças que se matriculam nas escolas, mas não permanecem ou progridem na escolaridade. Além disso, a atuação de psicólogos não se consolida como uma política que seja importante para alterar essa realidade.

\section{O psicólogo nesse cenário - atuação e formação}

As expectativas de intervenção do psicólogo na rede pública vêm demonstrando que a sociedade ainda espera do profissional a função de ajustar os estudantes ao sistema e, ao responder a esse tipo de demanda, o psicólogo se compromete com a reprodução das relações instituídas e funciona como legitimador da desumanização do homem, quando seu trabalho reproduz ou mantém a exclusão (Branco, 1998).

Durante muito tempo permaneceu a ideia de que a prática do psicólogo escolar deveria estar pautada na avaliação de crianças e jovens com dificuldades de aprendizagem por meio de instrumentos psicológicos que medissem a capacidade dos alunos, separando os aptos dos não aptos para a aprendizagem (Patto, 1990).

Esse paradigma, instituído pelos psicólogos escolares e educadores, bem como pela formação que envolve esse profissional ao longo de décadas, foi bastante explorado pela literatura produzida na área (Almeida, 2002, 2003; Andaló, 1984; Gomes, 2002; Guzzo, 1996; Machado, 2004, 2005; Machado \& Souza, 2001; Maluf, 1994; Maluf \& Cruces, 2008; Marinho-Araújo \& Almeida, 2008; Tanamachi, 2000; Torezan, 1999). De acordo com Guzzo e cols. (2007), a atuação desse profissional é influenciada por políticas educacionais que impedem a presença do profissional nos espaços educativos, tornando-se difícil, assim, a análise desses elementos, já que a análise da realidade concreta deveria se pautar em práticas concretas de psicólogos escolares.

Esse quadro, ao longo dos últimos anos, desde a formalização da Psicologia como profissão, em 1962, configura-se numa situação complexa marcada por encontros e desencontros entre Psicologia e Educação diante de diferentes posições ideológicas, conceituais e práticas. Vive-se, portanto, um movimento de tentar superar esse modelo de atuação e de produção de pesquisas, que enfatizam problemas como próprios dos indivíduos e que não fazem críticas às condições crescentes de desigualdade e exclusão, naturalizando essa condição (Cruces, 2003; Marinho-Araújo \& Almeida, 2008; Meira \& Antunes, 2003a; Meira \& Antunes, 2003b; Meira \& Facci, 2007). 
Durante muito tempo, a única prática do psicólogo conhecida por educadores foi centrada no modelo médico de atendimento de crianças em clínicas de psicologia. Embora a Psicologia tenha se constituído enquanto profissão, no Brasil, há quase 50 anos, o psicólogo escolar não tem ainda uma posição estabelecida dentro do sistema educacional. Isso significa que ele fica alocado em secretarias de saúde e de assistência social, mas, raramente, no serviço público, dentro da própria escola (Guzzo \& cols., 2007).

Assim, a história da Psicologia Escolar Educacional deve ser pensada, não apenas levando em conta alguns indicadores quantitativos do sistema educacional resultantes de políticas públicas que propõem a universalização do ensino, mas a partir de raízes históricas centradas na teoria da carência cultural, conforme apontada por Patto (1990). Esse fundamento se traduziu pela legitimação de preceitos clínicos, ou seja, na realização de práticas individualizantes dentro de espaços educacionais que propagam a ideia, especialmente para os educadores, de que questões educacionais centram-se em problemas dos alunos ou, no máximo, de suas famílias.

Para Marinho-Araújo (2009a), um levantamento realizado pelo Conselho Federal de Psicologia, no ano de 2004, demonstrou que apenas $11 \%$ dos psicólogos inscritos exerciam atividades relacionadas à Psicologia Escolar. Ainda para essa autora, as publicações na área da Psicologia Escolar, no entanto, demonstram que a atuação desse profissional, embora em número significativamente pequeno, vem se consolidando e propondo novas formas de intervenções, não apenas nas escolas, mas em todo o contexto educativo indiretamente relacionado ao contexto escolar.

De acordo com Tanamachi (2000), somente a partir da década de 1990 é que a grande diversidade do trabalho do psicólogo educacional, para além dos muros da escola, trouxe reflexões mais críticas acerca da formação e atuação desse profissional. Essas últimas décadas foram mais marcadas por novos encontros entre Psicologia e Educação, assumindo um direcionamento dialético da compreensão do desenvolvimento humano e não apenas das dificuldades de aprendizagem e comportamento, mas que perpassam ambientes mais amplos do contexto educacional como, por exemplo, espaços comunitários, núcleos, associações, entre outros.

A atuação dos psicólogos escolares tem defendido a escola em sua função social e política como espaço marcado por diversas contradições, mas também como possibilidade de criação de uma sociedade mais justa, conforme discute Marinho-Araujo (2009b). Por isso, destaca-se sua importância enquanto local de atuação para o psicólogo escolar, mas não restrito a ela.

Ao psicólogo escolar cabe a função de contribuir, junto com educadores, para a promoção da aprendizagem e do desenvolvimento das crianças, a partir de uma perspectiva mais integral do sujeito do que vem enfatizando a escola. $\mathrm{Ou}$ seja, além do desenvolvimento cognitivo, deve-se promover o desenvolvimento emocional, social e motor por meio de intervenção com as crianças, suas famílias e comunidade. Essa perspectiva foi o que motivou a criação da Associação Brasileira de Psicologia Escolar (ABRAPEE), em 1990, que, no entanto, apesar de sua consolidação com a promoção de eventos da área e edição de uma revista científica específica, ainda não conseguiu um impacto essencial na aproximação entre os profissionais de Psicologia e as escolas. Antes disso, a Psicologia Escolar era uma área de aplicação da Psicologia, definida como obrigatória pelo Currículo Mínimo estabelecido pelo Conselho Federal de Educação, em 1962, pelo parecer 403/62; hoje é apenas uma formação eletiva aos estudantes que cursam a graduação em Psicologia. O Currículo Mínimo foi mantido quase que sem modificações até que a Lei de Diretrizes e Bases - LDB (Ministério da Educação, 1996) mudasse essa condição. Os Currículos Mínimos foram extintos e em seu lugar estabelecidas Diretrizes Curriculares Nacionais - DCNs (Ministério da Educação, 2004) que, por meio do estabelecimento dos Núcleos Comuns e áreas de ênfases curriculares ou de aprofundamento de estudos, acabam definindo que os cursos de graduação em Psicologia devem oferecer, no mínimo, duas ênfases para formação do psicólogo. Essa situação diversifica a formação dos estudantes no território nacional, propiciando isonomia na certificação profissional, porém com distintas possibilidades de estudo e prática profissional. Ao mesmo tempo, mantém a formação clínica como predominante na maioria dos cursos de graduação do país. A situação não muda, apesar de mudarem as políticas.

Em 2007, o Conselho Federal de Psicologia reconhece a Psicologia Escolar como uma especialidade, sem que nenhum passo tenha sido dado para o reconhecimento da importância do psicólogo dentro das escolas, sobretudo pelos educadores. Com esse reconhecimento, fica marcado o modelo de atuação do psicólogo no âmbito da educação formal, com a realização de pesquisas, diagnóstico e intervenção preventiva ou corretiva em grupo e individualmente, como se fosse possível uma mudança da realidade apenas por uma resolução tirada no âmbito da entidade da categoria profissional.

Coerente com a questão apontada acima, Gomes (2002) aponta que traçar um perfil da atuação do psicólogo escolar no Brasil tem sido muito complicado, tendo em vista que existe uma distância entre o papel atribuído ao psicólogo no campo teórico e as demandas que se espera sejam atendidas no cotidiano da escola. Portanto, há a necessidade de se contextualizar a ação do psicólogo na realidade educacional e social brasileira, ao mesmo tempo em que se institui sua regulamentação para atuação nos espaços educativos.

É preciso que sejam criadas referências para a atuação do psicólogo no contexto da escola, mas há também dificuldade em delinear um perfil de atuação profissional, bem como de articular a prática à teoria (Marinho-Araújo \& Almeida, 2008). Essas autoras apontam que a ausência de articulação entre teoria e prática tem sido relacionada às deficiências na formação do profissional e propõem a introdução do ensino de pesquisa no contexto da graduação universitária como requisito essencial à formação do psicólogo escolar.

AAssociação Brasileira de Ensino de Psicologia (ABEP), criada com a finalidade de acompanhar a formação profissional, vem produzindo debates que, por um lado, apoiam a importância de Diretrizes e por outro, tornam evidente a necessidade de maior aprofundamento de seu conteúdo pelo próprio corpo docente e coordenadores de curso e suas estruturas curriculares. Mesmo carregada de boas intenções, a ABEP não consegue organizar um debate nacional sobre a formação do profissional de Psicologia, que responda às necessidades e características da realidade brasileira. As discussões ampliam 
as possibilidades de se estruturar a formação, diversificando os espaços de aprendizagem, criando mecanismos de integração e ampliando a interação, de modo a desenvolver habilidades e competências transversais. No entanto, continua a proliferação de cursos de formação básica em Psicologia, sem qualquer critério de qualificação profissional, o que dificulta uma ação política de maior abrangência e consequência.

Souza (2007) aponta que é das Instituições de Ensino Superior (IES) que surgem experiências acerca da formação em Psicologia Escolar e atuação dos profissionais e que, portanto, faz-se necessário indagarmos a respeito de como se tem dado a apropriação dos conhecimentos produzidos dentro desses espaços acadêmicos pelos profissionais que se encontram na rede pública de ensino. A autora ainda lança questionamentos acerca de quais políticas vêm sendo geradas por essa atuação frente à demanda escolar, fazendo-nos perceber a distância existente entre a teoria e a prática nessa área.

A oportunidade de formar psicólogos escolares reveste-se de grandes desafios, tendo em vista as dificuldades presentes nas estruturações curriculares dos cursos na formação inicial do psicólogo e na crescente despolitização que estudantes e professores revelam por suas produções e intervenções na realidade. É urgente a necessidade de se repensar uma formação voltada para atuação profissional politicamente mais comprometida com a demanda dos contextos educacionais brasileiros (Guzzo, Costa \& Sant'Ana, 2009).

De acordo com Meira (2000), o pensamento crítico presente atualmente na Educação a coloca para além da posição de instrumento reprodutor da sociedade. As relações com a sociedade e as diversas áreas do conhecimento tornam a Educação um espaço onde conflitos e rupturas, em uma perspectiva dialética e contraditória, podem possibilitar processos emancipatórios e de transformação. É por representar um espaço repleto de diferentes mediações e múltiplas determinações, que a realidade educacional retoma sua importância social enquanto instância essencial para compreensão de práticas e conhecimento historicamente acumulados.

Um avanço no que se refere a esse pensamento hegemônico foi ressaltado por Tanamachi (1992). Essa autora indica a existência de publicações de diversos autores sobre uma compreensão mais crítica da Psicologia, especialmente no campo educacional, desde o início da década de 1980. Guzzo (1999) aponta a necessidade de transformação do psicólogo escolar para um profissional com formação política mais consistente, o que poderia ocorrer, principalmente, por meio de mudanças em sua formação acadêmica. No que diz respeito à organização da área de Psicologia Escolar, mais especificamente a partir de 1999, foi criado um Grupo de Trabalho em Psicologia Escolar/ Educacional na Associação Nacional de Pesquisa e Pós-Graduação em Psicologia (ANPEPP). Esse grupo vem produzindo, nos últimos anos, publicações que também denotam uma preocupação em contribuir para essa discussão a partir de relatos dos participantes sobre a pesquisa, a formação e a prática do psicólogo escolar, contemplando uma variedade de áreas e eixos temáticos (Almeida, 2003; Campos, 2007; Del Prette, 2001; Guzzo, 1999, 2009; Marinho-Araújo 2007, 2009a; Martínez, 2005; Wechsler, 2008).

Esses são estudos que representam um esforço em direção à transformação da formação e atuação do psicólogo escolar e educacional, mas que podem ser considerados avanços na busca de novos horizontes.

\section{Os Fundamentos Teóricos e os Compromissos Assumidos com a Produção Científica: Como e Para Quê?}

O corpo de conhecimento que a Psicologia produz é uma fonte importante na análise da história da relação entre Psicologia e Educação, porque evidencia diversos elementos presentes na forma como o pesquisador fundamenta seus estudos e compreende a realidade. Ao fazer uma investigação sobre a Psicologia Escolar e Educacional no Brasil, pudemos constatar que esta é uma temática presente na literatura educacional. Alguns levantamentos já foram realizados no passado sobre essa área com o objetivo de conhecer o estado da produção científica (e.g., Neves, Almeida, Chaperman \& Batista, 2002; Oliveira, Catolice, Joly \& Santos, 2006; Santos \& cols., 2003).

Alguns estudos procuraram sistematizar a presença de pesquisas da área em eventos específicos ou veículos científicos de divulgação do conhecimento. O levantamento de Santos, Oliveira, Joly e Suehiro (2003), ao analisar as produções científicas apresentadas no I Congresso Nacional de Psicologia Ciência e Profissão, constatou que as principais temáticas relacionadas à área centravam-se nas necessidades especiais, formação do educador e orientação profissional. Com relação à modalidade de pesquisa, predominou o relato de pesquisa seguido do relato de experiência. A respeito da análise dos dados, a análise qualitativa correspondeu a $49 \%$, as quantitativas, a $40 \%$, e as mistas (qualitativa e quantitativa), a $4 \%$, sendo que os trabalhos que não especificaram as abordagens utilizadas corresponderam a 7\%.

Já a investigação de Oliveira, Catolice, Joly e Santos (2006), sobre a produção científica de 10 anos (1996-2005) da revista Psicologia Escolar e Educacional, identificou que as principais temáticas estudadas foram: testes/construção de instrumentos, método de ensino/aprendizagem, leitura, criatividade e aspectos afetivos/ emocionais, inteligência/ raciocínio/cognição, Psicologia Escolar e relação família/ escola, entre outros. Com relação à escolaridade dos participantes, o Ensino Superior e o Ensino Fundamental são os mais presentes nas pesquisas.

Essas investigações contribuíram para a análise das pesquisas na área da Psicologia Escolar e Educacional no Brasil e acrescentam elementos para uma reflexão da história que vem sendo produzida na área. Para complementar essas informações e fundamentar a crítica de como vem sendo construída essa história, buscamos sistematizar a produção na única revista brasileira que concentra, como linha editorial, os estudos e pesquisas provenientes da área da Psicologia Escolar. Mesmo sabendo que uma revista científica nem sempre se mantém fiel à sua linha editorial, essa breve revisão feita na revista Psicologia Escolar e Educacional, no período de 1996 a 2009, tem o objetivo de apontar os passos da produção científica da área nessa última década. Mesmo reconhecendo os limites de um levantamento como este para uma análise aprofundada da história da produção científica nacional, podemos dizer que alguns elementos encontrados se 
configuraram como importantes para a síntese que buscamos fazer sobre o corpo de conhecimento produzido e sua relação com as demandas da realidade.

Iniciamos com a busca das publicações que se encontravam na modalidade "Artigo", no período examinado, e destes, os que tratavam da Psicologia Escolar, totalizando 23 produções para a análise. Cada artigo foi estudado com base em uma Ficha de Análise dos Artigos, de tal forma que pudéssemos organizar nossas reflexões para o presente trabalho (ver Anexo 1). Em seguida, foram investigadas as linhas de pesquisa dos 58 autores envolvidos com os artigos selecionados, com o objetivo de identificar a abordagem teórica. Apenas 46 dos 58 autores estavam envolvidos em uma linha de pesquisa relacionada à área de conhecimento. As linhas foram identificadas e organizadas para análise.

Ao identificar a produção específica por ano na revista estudada, verificamos oscilações no número de artigos publicados por ano, mas a produção nos últimos cinco anos foi superior $(52,3 \%)$ àquela dos cinco anos anteriores $(30,2 \%)$, conforme mostrado na Tabela 1 . No que se refere à modalidade de pesquisa, prevaleceram o relato de pesquisa $(39 \%)$ e o estudo teórico (35\%), seguidos pela revisão da literatura (17,5\%) e pelo relato de experiência profissional (8,5\%). Isso denota que as pesquisas advindas da experiência profissional ainda não têm sido destaque nessa área, apesar de existirem diversas produções que discutem o papel e a atuação do psicólogo escolar, revelando uma prevalência teórica $(52,5 \%)$ na discussão desse tema.

Tabela 1. Número de artigos (N) por ano publicados na revista Psicologia Escolar e Educacional.

\begin{tabular}{ccc}
\hline Período & N & \% \\
\hline 1999 & 4 & 17,50 \\
2000 & 1 & 4,30 \\
2001 & 1 & 4,30 \\
2002 & 1 & 4,30 \\
2003 & 1 & 4,30 \\
2004 & 3 & 13,00 \\
2005 & 3 & 13,00 \\
2006 & 2 & 8,75 \\
2007 & 1 & 4,30 \\
2008 & 2 & 8,75 \\
2009 & 4 & 17,50 \\
TOTAL & 23 & 100 \\
\hline
\end{tabular}

Essa caracterização reflete, sem dúvida, uma conjuntura política e social que ainda não delimita o espaço do psicólogo escolar na rede pública, enquanto cargo estabelecido na maioria das regiões do país. Os dispositivos legais que circunscrevem essa implementação possuem textos pouco contundentes, como é o caso da LDB, que não regulamenta a função do psicólogo e situa os seus serviços dentre outras formas de assistência social. Pesquisas recentes, como a de
Martínez (2007), por outro lado, revelam que o psicólogo não tem ocupado os espaços de deliberação política e tem se distanciado dos debates nacionais sobre as políticas públicas de educação.

Com relação às pesquisas empíricas, os estudantes universitários foram os participantes mais frequentes $(62,5 \%)$. Da mesma forma, entre 1995 e 2004, estudos sobre a avaliação psicológica no contexto escolar tiveram como participantes da pesquisa estudantes universitários e alunos do Ensino Fundamental, conforme resultados do levantamento feito por Oliveira e cols. (2007). Observamos, também, que os instrumentos de coleta de dados mais utilizados foram entrevistas, questionários e escalas, sendo os dados obtidos analisados por meio de técnicas estatísticas ou a partir de procedimentos de análise de discurso ou de conteúdo.

Esses achados coincidem com a crítica apresentada por Parker (2007) à história da Psicologia e sua conformação na atualidade - uma ciência comprometida com a manutenção da ordem capitalista que pouco ou nada contribui para sua transformação. Segundo esse autor, a prevalência de uma abordagem quantitativa na produção do conhecimento não revela elementos da realidade concreta porque se concentra em descrições pouco ou nada refletidas sobre alguns segmentos dessa mesma realidade. A maioria dos estudos por ele analisados utilizou estudantes universitários como participantes, o que, segundo a sua concepção, acaba contribuindo para uma visão reducionista e parcial da realidade. Em outras palavras, esse tipo de produção, que mais concorre com um produtivismo voltado ao coroamento de pesquisadores isolados, em nada contribui para uma construção histórica compromissada com a mudança da realidade.

Sampaio (2010), ao fazer uma análise das pesquisas que fizeram levantamentos na área da Psicologia Escolar, mostrou-se curiosa com a conclusão de que o nível escolar mais estudado ao longo desses últimos 10 anos (1999 a 2009) tem sido o Ensino Superior. Para essa autora, as pesquisas não se voltam para o Ensino Superior porque enxergam uma prioridade ou zona de alto interesse, mas porque os participantes mais disponíveis têm sido os alunos dos cursos de graduação, tornando-se uma situação confortável para quem coleta os dados. Assim, conforme considera a autora:

os trabalhos analisados não tinham como foco e temática questões relativas à Educação Superior, os informantes desses estudos é que eram universitários, especialmente iniciantes ou concluinte. (Sampaio, 2010, p. 98)

No entanto, é importante considerar que uma reflexão recente, conduzida por Marinho-Araújo (2009a), retrata a imersão da área da Psicologia Escolar no campo do Ensino Superior. A autora sugere que essa remodelação nas frentes de atuação reflete a ampliação das demandas contemporâneas pelos estudos desenvolvidos no âmbito da Psicologia Escolar/ Educacional. O entendimento de que as instituições educativas, quaisquer que sejam elas, concretizam as relações entre educação, sociedade, subjetividade e cidadania têm guiado e motivado a inserção de estudos e pesquisas no contexto do Ensino Superior, bem como nos demais níveis de ensino, até a educação informal. 
Um aspecto que chama a atenção, ao analisarmos a produção científica da área nesses últimos 10 anos, é a abordagem teórica que serve de fundamento a esses estudos. Algumas puderam ser identificadas por terem sido mencionadas nos próprios trabalhos ou nas linhas de pesquisas dos autores. Dentre elas, as abordagens histórico-cultural e cognitiva foram as mais indicadas nos artigos encontrados, conforme indicado na Tabela 2. Uma análise dos temas estudados mostra que, em 10 anos, a área ainda reflete sobre a relação entre Psicologia e Educação, sobre a formação e atuação do profissional de psicologia nesse campo, sobre a produção científica na área e sobre a Psicologia Educacional como disciplina nos cursos de formação de licenciatura. Poucas são as construções e exercícios teóricos sobre categorias importantes relacionadas à realidade educacional brasileira, como violência na escola, processos de exclusão, dentre outras.

Interessante notar que, em relação à autoria dos artigos, no ano de 1999, a maioria das produções era individual, enquanto, nos últimos três anos, a maioria dos artigos teve autoria coletiva, predominando aqueles com quatro autores, conforme apresenta a Tabela 3. Isso revela uma resposta rápida às políticas educacionais referentes à produção científica na pós-graduação, que estimula a publicação de trabalhos dos pesquisadores e seus estudantes.

É importante considerar que ainda há uma distância na produção entre a pós-graduação e a graduação: dos 23 artigos, apenas $4(17,5 \%)$ corresponderam a pesquisas realizadas entre professores de pós-graduação e alunos de graduação (ver Tabela 4). Estudantes de pós-graduação têm como meta a formação em pesquisa e para o Ensino Superior e, de acordo com a atual política educacional, precisam produzir conhecimento no âmbito de seu grupo de pesquisa. Com isso, a produção na área de Psicologia Escolar também revela que doutores, mestres e estudantes de pós-graduação têm sido responsabilizados pela autoria da produção na área (72\%), conforme indicado na Tabela 5.

Como a pesquisa brasileira ainda se concentra em instituições de Ensino Superior, dentro, portanto, dos cursos de pós-graduação, a produção na área da Psicologia Escolar não difere dessa constatação. A produção avaliada apresentou-se concentrada em $52 \%$ de universidades privadas e $48 \%$ de universidades públicas, predominantes nas regiões sudeste, centro-oeste e sul. É importante destacar que o acúmulo da produção científica na região sudeste deve-se ao fato de que essa região é a que concentra a maior parte dos cursos de psicologia no país (Yamamoto, Souza \& Yamamoto, 1999). Outros elementos que chamam a atenção nessa análise da produção científica na área são o financiamento das pesquisas e as referências mais utilizadas. Quanto ao financiamento das pesquisas, é importante notar a presença das agências de fomento: $12 \%$ são financiadas pelo Conselho Nacional de Desenvolvimento Científico e Tecnológico (CNPq), 8\% pela Coordenação de Aperfeiçoamento de Pessoal de Nível Superior (CAPES), 8\% pelo Programa Institucional de Bolsas de Iniciação Científica (PIBIC) e 4\% pela Fundação de Amparo à Pesquisa do Estado de São Paulo (FAPESP), sendo que $68 \%$ não mencionaram se tiveram apoio financeiro. Isso revela que as agências sustentam parte da produção na área, pelo menos sob forma de apoio ao estudante de pósgraduação, graduação ou grupos de pesquisa, mesmo que ainda incipiente. $\mathrm{O}$ outro elemento diz respeito às referências utilizadas - grande parte delas ainda internacionais (42\%). Em geral, tanto nas referências nacionais quanto nas internacionais, prevaleceram artigos, capítulos de livros e depois livros, teses e dissertações. Apesar de existirem publicações nacionais, a área da Psicologia Escolar e Educacional ainda se utiliza de fundamentos teóricos e produções internacionais para discutir algumas temáticas da realidade brasileira.

Diante destes dados, uma síntese possível é que, distante da realidade concreta, a produção científica da área parece mais voltada a sustentar a produção de programas de pósgraduação, seus estudantes e professores, do que de fato problematizar a área com outros setores e produzir substratos teóricos para a mudança da realidade. O psicólogo não está presente nas escolas e, por isso, produz um conhecimento que tangencia os verdadeiros problemas da área.

\section{Os Resultados Dessa Caminhada: Olhando Para o Futuro}

Parece difícil uma análise das possibilidades de futuro para a pesquisa brasileira, em especial a pesquisa na área da Psicologia Escolar, ou Psicologia no campo educativo, porque temos clareza de que a realidade educacional brasileira não se modificará pela ação da Psicologia em seu interior.

Tabela 2. Número de artigos (N) em função das abordagens teóricas (*).

\begin{tabular}{llc}
\hline Abordagem teórica & N & \% \\
\hline Psicologia histórico-cultural & 13 & 28,0 \\
Processos cognitivos & 11 & 24,0 \\
Teorias motivacionais & 4 & 8,5 \\
Representações sociais & 2 & 4,5 \\
Psicologia da aprendizagem & 2 & 4,5 \\
Gestalt, psicometria, psicologia crítica e psicanálise & 4 & 8,5 \\
Não mencionado & 10 & 22,0 \\
TOTAL & 46 & 100 \\
\hline
\end{tabular}

(*) Um mesmo artigo pode ter indicado mais de uma abordagem teórica. 
Tabela 3. Número de autores (N) por artigo nos anos de 1999 a 2009.

\begin{tabular}{ccccccccccc}
\hline Ano & 1 autor por artigo & 2 autores por artigo & 3 autores por artigo & 4 autores por artigo & & Total \\
& $\mathbf{N}$ & $\mathbf{\%}$ & $\mathbf{N}$ & $\mathbf{\%}$ & $\mathbf{N}$ & $\mathbf{\%}$ & $\mathbf{N}$ & $\mathbf{\%}$ & $\mathbf{N}$ & $\mathbf{\%}$ \\
\hline 1999 & 3 & 13,0 & 1 & 4,3 & 0 & 0 & 0 & 0 & 4 & 17,4 \\
2000 & 1 & 4,3 & 0 & 0 & 0 & 0 & 0 & 0 & 1 & 4,3 \\
2001 & 0 & 0 & 1 & 4,3 & 0 & 0 & 0 & 0 & 1 & 4,3 \\
2002 & 0 & 0 & 0 & 0 & 1 & 4,3 & 0 & 0 & 1 & 4,3 \\
2003 & 0 & 0 & 0 & 0 & 0 & 0 & 1 & 4,3 & 1 & 4,3 \\
2004 & 0 & 0 & 1 & 4,3 & 1 & 4,3 & 1 & 4,3 & 3 & 13,0 \\
2005 & 0 & 0 & 2 & 8,7 & 1 & 4,3 & 0 & 0 & 3 & 13,0 \\
2006 & 0 & 0 & 1 & 4,3 & 0 & 0 & 1 & 4,3 & 2 & 8,8 \\
2007 & 0 & 0 & 0 & 0 & 0 & 0 & 1 & 4,3 & 1 & 4,3 \\
2008 & 0 & 0 & 1 & 4,3 & 0 & 0 & 1 & 4,3 & 2 & 8,8 \\
2009 & 1 & 4,3 & 1 & 4,3 & 0 & 0 & 2 & 8,7 & 4 & 17,4 \\
TOTAL & 5 & 21,7 & 8 & 34,8 & 3 & 13,0 & 7 & 30,5 & 23 & $100 \%$ \\
\hline
\end{tabular}

Tabela 4. Número de artigos (N) em função da natureza da autoria.

Natureza da autoria

$\mathrm{N} \quad \%$

Professores de graduação

29

Professores de pós-graduação

$4 \quad 17,5$

Professores de graduação e estudantes de graduação

Professores de pós-graduação e estudantes de pós-graduação

Professores de pós-graduação, estudantes de pós-graduação e estudantes de graduação

Não foi possível identificar

TOTAL
Ao mesmo tempo, é preciso que cumpramos o papel de construirmos as bases para que a Psicologia, nessa área de aplicação, possa mais do que descrever a realidade de forma acrítica distante e protegida nos programas de pósgraduação; para que, de fato, se insira nessa realidade de forma concreta e, assim, colabore para que relação entre teoria e prática fecunde mudanças reais, tanto para a formação dos psicólogos quanto para sua contribuição para o cotidiano das escolas.

No entanto, é preciso reconhecer que, quando buscamos um corpo de conhecimento que nos ajude a melhor compreender a realidade e iluminar os caminhos que devemos percorrer, devemos encontrar uma produção que se aplique à nossa realidade - uma psicologia crítica. E essa produção crítica deve ter critérios diferenciados de validade de teorias científicas e práticas profissionais, quais sejam: a preocupação constante com a realidade social imediata; a vocação emancipadora, que se funda no processo de tomada de consciência sobre a vida nas condições de exploração e dominação; e o caráter reflexivo, que se pauta no realismo crítico contrário ao relativismo, no combate da razão científica a serviço do poder político e econômico. Para Martín-Baró (1996), a validade de uma teoria não se mede por critérios lógicos ou epistemológicos, mas por sua capacidade de explicar ontologicamante a realidade.

A produção hegemônica na Psicologia Escolar e Educacional justifica as dificuldades e os desafios que são colocados para a área - uma produção que não é práxis, não se compromete com a realidade concreta e não se dispõe a refletir 
Tabela 5. Número de autores $(\mathrm{N})$ em função de sua qualificação.

\begin{tabular}{lcc}
\hline Qualificação dos autores & N & \% \\
\hline Doutor & 25 & 43 \\
Mestre & 5 & 8,5 \\
Doutorandos & 5 & 8,5 \\
Mestrandos & 7 & 12 \\
Estudantes de graduação & 9 & 16 \\
Não identificado & 7 & 12 \\
TOTAL & 58 & 100 \\
\hline
\end{tabular}

para buscar caminhos, principalmente porque está distante de uma análise que inclui elementos históricos, políticos e sociais do momento presente.

Impossível pensar em futuro sem que se tenha uma análise da realidade concreta que não se manifesta imediatamente: a realidade concreta precisa ser investigada. $\mathrm{E}$, a dialética nos propõe uma maneira de investigação da realidade que, segundo Kosik (1963/2002), distingue duas qualidades da práxis humana: agir objetiva e praticamente sobre a realidade dentro de um determinado conjunto de relações sociais e não apenas examinar essa mesma realidade como um abstrato sujeito congoscente. A práxis a que nos referimos é historicamente determinada, baseada na divisão social do trabalho, na divisão da sociedade em classes sociais e nas hierarquias de posições sociais que sobre elas se erguem. Conhecer a realidade concreta é agir sobre ela e, para isso, combater o mundo das aparências. E, ainda segundo Kosik, esse combate se dá pela crítica revolucionária da práxis da humanidade que coincide com o processo de humanização dos homens, pelo pensamento dialético que dissolve o fetiche da aparência para atingir a realidade e a realização da verdade e criação da realidade humana por um processo de construção de possibilidades.

Dificilmente a análise histórica de uma área do conhecimento pode se eximir de uma crítica aos elementos que foram identificados como presentes nessa trajetória. É preciso apontar que a Psicologia e os psicólogos brasileiros sempre estiveram próximos à realidade educacional, mesmo que em número bastante reduzido, quando se considera a totalidade da área. Milhares de psicólogos são formados no Brasil ainda com o viés da Psicologia voltada para a prática clínica e tratamento da doença, fundada no modelo médico e sob os enfoques do positivismo, do pós-modernismo acrítico e da ideologia da sociedade burguesa.

O rompimento com essa posição histórica e a construção de alternativas para a Psicologia passa, necessariamente, pela constatação e combate aos elementos ideológicos presentes em seu interior. Como indica Parker (2007), a presença de elementos da ideologia burguesa no interior da Psicologia pode ser constatada pela tendência a atribuir peso excessivo a fatores individuais para explicar comportamentos sociais ou individuais; pela tendência a analisar problemas sociais como desajustamentos psicológicos, sem considerar a estrutura classista e socioeconômica do sistema social; e pela tendência a desconsiderar o potencial conformista das soluções e encaminhamentos teóricos e práticos da Psicologia, reduzindo a possibilidade de que os beneficiados desses conhecimentos ou serviços se tornem conscientes da importância de influências sociais adversas em suas vidas cotidianas.

Esta condição evidencia uma histórica luta e resistência ao impacto da ideologia sobre a prática profissional vigente. Resistir ao consultório particular, ao modelo médico de compreensão do fracasso escolar, aos elementos ideológicos presentes no corpo de conhecimento da Psicologia exigiu alguns movimentos importantes de disseminação do que significa entender a realidade brasileira a partir da inserção e presença no campo, não apenas pela vidraça da universidade, mas pelas experiências cotidianas de vida nesses espaços.

\section{Referências}

Albuquerque, R. C. (1995). Estratégia de desenvolvimento e combate à pobreza. Estudos Avançados (São Paulo), 9, 75-116.

Almeida, S. F. C. (2002). O psicólogo no cotidiano da escola: re-significando a atuação profissional. Em R. S. L. Guzzo (Org.), Psicologia escolar: LDB e educação hoje (2a ed) (pp. 77-90). Campinas: Alínea.

Almeida, S. F. C. (2003). Psicologia escolar: ética e competências na formação e atuação profissional. Campinas: Alínea.

Andaló, C. S. A. (1984). O papel do psicólogo escolar. Psicologia: Ciência e Profissão, 4, 43-46.

Benjamim, W. (1987). Obras escolhidas, Vol 1. Magia e técnica, arte e politica. Ensaios sobre literatura e história da cultura. São Paulo: Brasiliense.

Branco, M. T. C. (1998). Que profissional queremos formar? Psicologia: Ciência e Profissão, 18, 28-35.

Campos, H. R. (Org.). (2007). Formação em psicologia escolar: realidade e perspectivas. Campinas: Alínea.

Conselho Federal de Educação (1962). Parecer $n^{o}$. 403/62 - Currículo mínimo dos cursos de psicologia. Retirado em 13/09/2010, de http://www.abepsi.org.br/abepsi/linha_do_tempo/ memoria/docs/fr_1962_2.htm.

Conselho Federal de Psicologia (2007). Resolução CFP $N .^{\circ}$ 013/2007 - Consolidação das resoluções relativas ao título profissional de especialista em psicologia. Brasília: CFP.

Cruces, A. V. V. (2003). Psicologia e Educação: nossa história e nossa realidade. Em S. F. C. Almeida (Org.), Psicologia escolar: ética e competências na formação e atuação profissional (pp. 1736). Campinas: Alínea.

Del Prette, Z. A. P. (2001). Psicologia escolar e educacional: saúde e qualidade de vida, explorando fronteiras. Campinas: Alínea.

Gomes, V. L. (2002). A formação do psicólogo escolar e os impasses entre a teoria e a prática. Em R. S. L. Guzzo (Org.), Psicologia escolar: LDB e educação hoje. Campinas: Alínea.

Guzzo, R. S. L. (1996). Formando psicólogos escolares no Brasil: dificuldades e perspectivas. Em S. M. Wechsler (Org.), Psicologia escolar: pesquisa, formação e prática (pp. 75-92). Campinas: Alínea.

Guzzo, R. S. L. (1999). Psicologia escolar: LDB e educação hoje. Campinas: Alínea. 
Guzzo, R. S. L. (2009). Revolução na psicologia escolar: as demandas da realidade escolar e do profissional na escola. Em M. R. de Souza \& F. C. S. Lemos (Orgs.), Psicologia e compromisso social: unidade na diversidade, Vol. 1 (p. 304). São Paulo: Escuta.

Guzzo, R. S. L., Costa, A. S., \& Sant'Anna, I. M. (2009). Formando psicólogos escolares: problemas, vulnerabilidades, desafios e horizontes. Em C. M. Marinho-Araújo (Org.), Psicologia escolar: novos cenários e contextos de pesquisa, prática e formação (pp. 35-52). Campinas: Alínea.

Guzzo, R. S. L., Martinez, A. M., \& Campos, H. R. (2007). School psychology in Brazil. Em S. Jimerson, T. Oakland \& P. Farrell (Eds.), The handbook of international school psychology (pp. 29-37). London: Sage.

Januzzi, P. M. (2005) Indicadores para diagnóstico, monitoramento e avaliação de programas sociais no Brasil. Revista do Serviço Público (Brasília), 56, 137-160.

Kosik, K. (2002). Dialética do concreto ( $7^{\mathrm{a}}$ ed.) (C. Neves \& A. Toríbio, Trads.). Rio de Janeiro: Paz e Terra. (Trabalho original publicado em 1963)

Machado, A. M. (2004). Crianças de classe especial: efeitos do encontro da saúde com a educação (3a ed.). São Paulo: Casa do Psicólogo.

Machado, A. M. (2005). Educação inclusiva: direitos humanos na escola. São Paulo: Casa do Psicólogo.

Machado, A. M., \& Souza, M. P. R. (2001). Psicologia escolar: em busca de novos rumos (3a ed.). São Paulo: Casa do Psicólogo.

Maluf, M. R. (1994). Formação e atuação do psicólogo na educação: dinâmica de transformação. Em R. Achcar (Coord.), Psicólogo brasileiro: práticas emergentes e desafios para a formação (pp. 245-272). São Paulo: Casa do Psicólogo.

Maluf, M. R., \& Cruces, A. V. V. (2008). Psicologia educacional na contemporaneidade. Boletim da Academia Paulista de Psicologia, XXVI, 87-99.

Marinho-Araújo, C. M. (2007). A psicologia escolar nas diretrizes curriculares: espaços criados, desafios instalados. Em H. R. Campos (Org.), Formação em psicologia escolar: realidades e perspectivas (pp. 17-48). Campinas: Alínea.

Marinho-Araújo, C. M. (2009a). Psicologia escolar na educação superior: novos cenários de intervenção e pesquisa. Em C. M. Marinho-Araújo (Org.), Psicologia escolar - Novos cenários e contextos de pesquisa, formação e prática (pp. 155-202). Campinas: Alínea.

Marinho-Araújo, C. M. (2009b). Psicologia escolar: novos cenários e contextos de pesquisa, formação e prática. Campinas: Alínea.

Marinho-Araújo, C. M., \& Almeida, S. F. C. (2008). Psicologia escolar: construção e consolidação da identidade profissional $\left(2^{\mathrm{a}}\right.$ ed.). Campinas: Alínea.

Martín-Baró (1996). Writings for a liberation psychology (2a ed.). Cambridge: Harvard University.

Martínez, A. M. (2005). Psicologia escolar e compromisso social: novos discursos, novas práticas. Campinas: Alínea.

Martínez, A. M. (2007). O psicólogo escolar e os processos de implantação de políticas públicas: atuação e formação. Em H. R. Campos (Org.), Formação em psicologia escolar - Realidades e perspectivas (pp. 109-133). Campinas: Alínea.

Melo, L., Setti, R., Linas, L., \& Weber, D. (09/09/2010). Analfabetismo atinge 14,1 milhões de pessoas. Retirado em 13/09/2010, de http://www.ipea.gov.br/portal/index. php? option $=$ com_content $\&$ view $=$ article $\& i d=3641$.
Meira, M. E. M. (2000). Psicologia escolar: pensamento crítico e práticas profissionais. Em E. R. Tanamachi, M. Proença \& M. L. Rocha (Orgs.), Psicologia e educação: desafios teórico práticos (pp. 35-71). São Paulo: Casa do Psicólogo.

Meira, M. E. M., \& Antunes, M. A. M. (2003a). Psicologia escolar: teorias críticas. São Paulo: Casa do Psicólogo.

Meira, M. E. M., \& Antunes, M. A. M. (2003b). Psicologia escolar: práticas críticas. São Paulo: Casa do Psicólogo.

Meira, M. E. M., \& Facci, M. G. D. (2007). Psicologia históricocultural: contribuições para o encontro entre a subjetividade e a educação. São Paulo: Casa do Psicólogo.

Ministério da Educação (1993). Plano decenal de educação para todos: 1993 -2003. Brasília: MEC, Conselho Nacional de Educação, Câmara de Educação Superior.

Ministério da Educação (1996). Lei n ${ }^{\circ}$ 9.394, de 20 de dezembro de 1996 - Lei de Diretrizes e Bases da Educação Nacional. Retirado em 13/09/2010, de http://portal.mec.gov.br/seed/arquivos/pdf/ tvescola/leis/lein9394.pdf.

Ministério da Educação (1997). Parâmetros curriculares nacionais: introdução aos parâmetros curriculares nacionais. Brasília: MEC, Secretaria de Educação Fundamental.

Ministério da Educação (2004). Parecer CNE/CES 0062/2004, de 19 de fevereiro de 2004 - Diretrizes curriculares nacionais para os cursos de graduação em Psicologia. Brasília: MEC, Conselho Nacional de Educação.

Neves, M. M. B. J., Almeida, S. F. S., Chaperman, M. C. L., \& Batista, B. P. (2002). Formação e atuação em psicologia escolar: análise das modalidades de comunicações nos congressos nacionais de psicologia escolar e educacional. Psicologia: Ciência e Profissão, 22, 2-11.

Oliveira, K. L., Catolice, L. M., Joly, M. C. R., \& Santos, A. A. A. (2006). Produção científica de 10 anos da revista Psicologia Escolar e Educacional (1996/2005). Psicologia Escolar e Educacional, 10, 283-292.

Oliveira, K. L., Santos, A. A. A., Noronha, A. P. P., Boruchivitch, E., Cunha, A. C., Bardagi, M. P., \& Domingues (2007). Produção científica em avaliação psicológica no contexto escolar. Psicologia Escolar e Educacional, 11, 239-251.

Parker, I. (2007). Revolution in psychology - Alienation to emancipation. London: Pluto Press.

Patto, M. H. S. (1984). Psicologia e ideologia: uma introdução crítica à psicologia escolar. São Paulo: T. A. Queiroz.

Patto, M. H. S. (1990). A produção do fracasso escolar. São Paulo: Casa do Psicólogo.

Prilleltensky, I. (2003). Understanding, resisting, and overcoming oppression: Toward psychopolitcal validity. American Journal of Community Psychology, 31, 195-201.

Sampaio, S. M. R. (2010). A psicologia na educação superior: ausências e percalços. Em Aberto (Brasília), 23 , 95 - 105.

Santos, A. A. A., Oliveira, K. L., Joly, M. C. R. A., \& Suehiro, A. C. B. (2003). I Congresso Nacional de Psicologia - Ciência e profissão: o que tem sido feito na psicologia educacional. Psicologia Escolar e Educacional, 7, 135-144.

Santos, C., \& Rosas, R. (09/09/2010). Desigualdade cai, mas rendimento dos muito pobres sobe menos. Retirado em 13/09/2010, de http://www.ipea.gov.br/portal/index.php?option=com_content\& view $=$ article $\&$ id $=3640 \&$ Itemid $=75$

Souza, M. P. R. (2007). Reflexões a respeito da atuação do psicólogo no campo da psicologia escolar/educacional em uma perspectiva crítica. Em H. R. Campos (Org.), Formação em psicologia escolar: realidades e perspectivas (pp. 149-162). Campinas: Alínea. 
Tanamachi, E. R. (1992). Psicologia escolar: tendências e avanços da psicologia na educação escolar. Dissertação de Mestrado, UNESP, Marília.

Tanamachi, E. R. (2000). Mediações teórico-práticas de uma visão crítica em psicologia escolar. Em E. R. Tanamachi, M. Proença \& M. L. Rocha (Orgs.), Psicologia e educação: desafios teóricopráticos (pp. 73-103). São Paulo: Casa do Psicólogo.

Torezan, A. M. (1999). Psicologia escolar e a nova conjuntura educacional brasileira. Em R. S. L. Guzzo (Org.), Psicologia escolar: LDB e educação hoje (pp. 27-37). Campinas: Alínea.
Wechsler, S. M. (2008). Psicologia escolar: pesquisa, formação e prática ( $3^{\mathrm{a}} \mathrm{ed}$.). Campinas: Alínea.

Yamamoto, O. H., Souza, C. C., \& Yamamoto, M. E. (1999). A produção científica na psicologia: uma análise dos periódicos brasileiros no período 1990-1997. Psicologia: Reflexão e Crítica, 12, 549-565.

Yazlle, E. G. (1990). A formação do psicólogo escolar no estado de São Paulo: subsídios para uma ação necessária. Tese de Doutorado, Pontifícia Universidade Católica de São Paulo, São Paulo.

Anexo 1: Modelo da ficha de análise dos artigos.

\begin{tabular}{|c|c|}
\hline \multicolumn{2}{|l|}{ Título do artigo } \\
\hline Autores & \\
\hline Ano de publicação & \\
\hline Objetivo da pesquisa & \\
\hline Palavras-chave & \\
\hline $\begin{array}{l}\text { Método } \\
\text { 1. Tipo de pesquisa } \\
\text { 2. Tipo de Método } \\
\text { 3. Fontes de dados } \\
\text { 4. Participantes } \\
\text { 5. Instrumentos e materiais } \\
\text { 6. Procedimento de análise }\end{array}$ & \\
\hline $\begin{array}{l}\text { Referências } \\
\text { 1. Nacionais e internacionais } \\
\text { 2. Tipos de referências: Capítulo de livros, Livros, Dissertações, } \\
\text { Teses, Relatório técnico, Anais de congressos, entre outros. }\end{array}$ & \\
\hline Modalidade da pesquisa: & \\
\hline Apoio financeiro & \\
\hline $\begin{array}{l}\text { Universidade } \\
\text { 1. Pública ou privada } \\
\text { 2. Setor da universidade } \\
\text { 3. Região da Universidade }\end{array}$ & \\
\hline $\begin{array}{l}\text { Autorias } \\
\text { 1. Quantidade de autores } \\
\text { 2. Formação dos autores } \\
\text { 3. Discente ou docente }\end{array}$ & \\
\hline
\end{tabular}

